\title{
Elevated blood urea nitrogen is associated with recurrence of post-operative chronic subdural hematoma
}

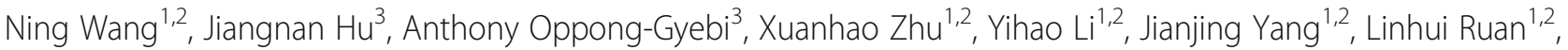
Qichuan Zhuge $e^{1,2}$ and Sheng $\mathrm{Ye}^{1,2^{*}}$ (D)

\begin{abstract}
Background: Chronic subdural hematoma (CSDH) is fundamentally treatable with about a 2-31\% recurrence rate. Recently, there has been renewed interest in the association between Blood Urea Nitrogen (BUN) and intracranial lesion. Therefore, this paper attempts to show the relationship between BUN and CSDH recurrence.

Methods: A total of 653 CSDH cases with Burr-hole Irrigation (BHI) were enrolled from December 2014 to April 2019. The analyzed parameters included age, gender, comorbidities, laboratory investigations, medication use and hematoma location. The cases were divided into recurrence and non-recurrence groups while postoperative BUN concentration was further separated into quartiles $(\mathrm{Q} 1 \leq 4.0 \mathrm{mmol} / \mathrm{L}, 4.0<\mathrm{Q} 2 \leq 4.9 \mathrm{mmol} / \mathrm{L}, 4.9<\mathrm{Q} 3 \leq 6.4 \mathrm{mmol} / \mathrm{L}$, $\mathrm{Q} 4>6.4 \mathrm{mmol} / \mathrm{L}$ ). Restricted cubic spline regressions and logistic regression models were performed to estimate the effect of BUN on $\mathrm{CSDH}$ recurrence.
\end{abstract}

Results: CSDH recurrence was observed in 96 (14.7\%) cases. Significant distinctions were found between recurrence and non-recurrence groups in postoperative BUN quartiles of cases $(P=0.003)$. After adjusting for the potential confounders, the odds ratio of recurrence was $3.069(95 \% \mathrm{Cl}=1.488-6.330, p=0.002)$ for the highest quartile of BUN compared with the lowest quartile. In multiple-adjusted spline regression, a high BUN level visually showed a significantly high $O R$ value of recurrence risk.

Conclusions: Elevated BUN at post-operation is significantly associated with the recurrence of CSDH, and it is indicated that high levels of serum BUN after evacuation may serve as a risk factor for CSDH recurrence.

Keywords: Chronic subdural hematoma, Blood urea nitrogen (BUN), Recurrence rate

\footnotetext{
*Correspondence: yesheng342@163.com

'Zhejiang Provincial Key Laboratory of Aging and Neurological Disorder

Research, The First Affiliated Hospital of Wenzhou Medical University, Wenzhou 325000, China

${ }^{2}$ Department of Neurosurgery, The First Affiliated Hospital of Wenzhou Medical University, Wenzhou 325000, Zhejiang, China

Full list of author information is available at the end of the article
}

(c) The Author(s). 2020 Open Access This article is licensed under a Creative Commons Attribution 4.0 International License, which permits use, sharing, adaptation, distribution and reproduction in any medium or format, as long as you give appropriate credit to the original author(s) and the source, provide a link to the Creative Commons licence, and indicate if changes were made. The images or other third party material in this article are included in the article's Creative Commons licence, unless indicated otherwise in a credit line to the material. If material is not included in the article's Creative Commons licence and your intended use is not permitted by statutory regulation or exceeds the permitted use, you will need to obtain permission directly from the copyright holder. To view a copy of this licence, visit http://creativecommons.org/licenses/by/4.0/. The Creative Commons Public Domain Dedication waiver (http://creativecommons.org/publicdomain/zero/1.0/) applies to the data made available in this article, unless otherwise stated in a credit line to the data. 


\section{Background}

Chronic subdural hematoma $(\mathrm{CSDH})$ is a frequently encountered neurosurgical disorder that is common among the aged. The incidence of CSDH is estimated to be $8.2-17.6$ per 100,000 persons per year which increases along with increasing age [1-3]. Burr-hole irrigation (BHI) is most widely used to treat $\mathrm{CSDH}$ with a relatively good outcome, but about $2-31 \%$ of patients relapse after the initial operation [1].

Factors found to influence CSDH recurrence have been reported in several studies, including age, Glasgow coma score (GCS), antiplatelet or anticoagulant agents, bilateral hematomas, postoperative pneumocephalus, and other certain related computed tomography $(\mathrm{CT})$ findings [4-7]. However, the findings of the connection between laboratory investigation and CSDH recurrence are still scarce.

Blood urea nitrogen (BUN) concentration is an easily overlooked investigation. Interestingly, there is a growing amount of literature that recognizes high $\mathrm{BUN} /$ creatinine $(\mathrm{Cr})$ as an independent risk factor of poor outcomes in acute ischemic stroke (AIS) patients [8-10]. Furthermore, elevated BUN concentration was revealed to increase in-hospital mortality in AIS patients [11]. These studies indicated that BUN was associated with intracranial disorders. But very little attention has been paid to the relationship between BUN and CSDH recurrence so far.

In this paper, variables associated with CSDH recurrence were investigated, focusing on the postoperative BUN concentrations of patients with CSDH who underwent evacuation at a single facility from 2014 to 2019 . This research aimed to explore the relationship between serum BUN levels and CSDH recurrence to provide a new orientation to study the pathophysiology of CSDH.

\section{Methods}

\section{Patients and parameters}

This study enrolled admitted patients with the diagnosis of CSDH at the First Affiliated Hospital of Wenzhou Medical University, Zhejiang province, China, between December 2014 and April 2019. Patients with CSDH were diagnosed by head magnetic resonance imaging (MRI) and CT. The following exclusive criteria were used:(1) without surgical treatment;(2) younger than 18 years old;(3) severe epilepsy;(4) severe renal or blood diseases;(5) hematoma organized or bad operation result;(6) craniotomy or evacuated by other departments;(7) lack of laboratory investigation;(8) hospital mortality. Patient with two operations was defined as two cases.
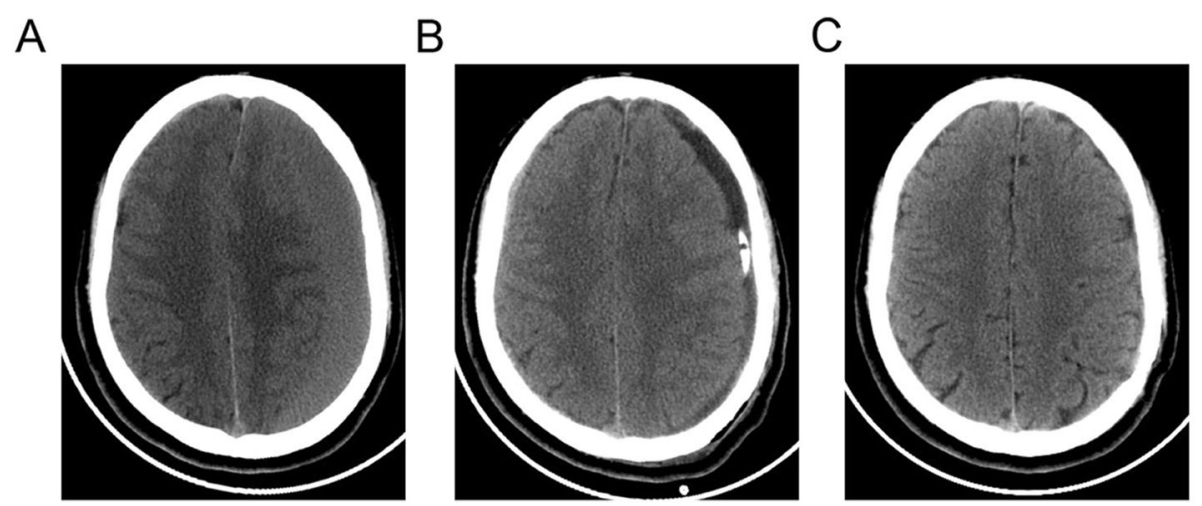

D

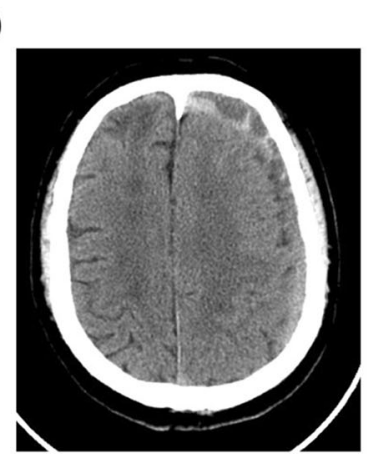

$E$

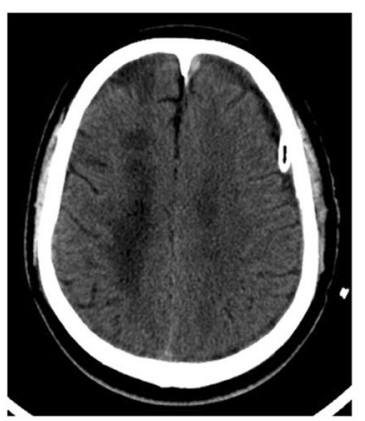

$\mathrm{F}$

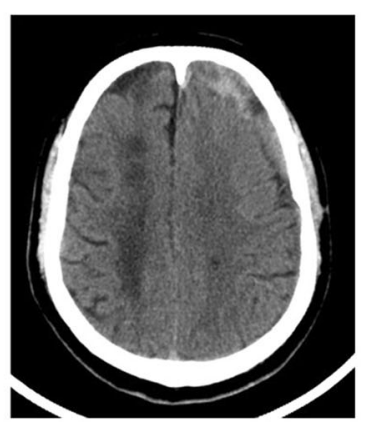

Fig. 1 CT imagings of two typical patients without and with recurrence of CSDH. a, the preoperative presentation of patient A without recurrence; $\mathbf{b}$ the imaging of the same patient within $48 \mathrm{~h}$ postoperatively; $\mathbf{c}$ the CT scan at 3-month follow-up of the patient A; d the presurgical imaging of patient B with recurrence of $\mathrm{CSDH}$; e the presentation of patient B within 48 h postoperatively; $\mathbf{f}$ the $\mathrm{CT}$ scan of patient B at 2 months after operation, a significant increase volume of subdural collection could be seen in left side 
The following clinical characteristics were analyzed: age, gender, demographic parameters, comorbidities, postoperative laboratory investigations, postoperative medication use, location of hematoma, and preoperative BUN level. Glasgow outcome scale (GOS) at discharge was performed to evaluate the neurologic function of patients.

\section{Surgery procedure and follow-up}

All patients underwent BHI with general anesthesia. After burr-hole exposure, dura incision and irrigation, we used closed system drainage with a subdural catheter connected to a vacuum plastic bag. Most catheters were withdrawn within $72 \mathrm{~h}$ after the operation. Head CT was performed within the first $48 \mathrm{~h}$ and on day 6 or 7 postoperatively. For good measure, patients were followed up with head CT at 3 months at the outpatient service.

\section{Definition of recurrence and grouping}

$\mathrm{CSDH}$ recurrence was evaluated by radiological criteria, which included an increased volume of the subdural collection and brain compression on either side within 3 months compared with those first measured after surgery through CT scans, and clinical criteria in which preoperative symptoms and signs abided or recurred (Fig. 1). The classification of recurrence was determined by two experienced neurosurgeons who were blinded to the study.

The cases were first divided into 2 groups according to recurrence and non-recurrence to investigate the risk factors for $\mathrm{CSDH}$ recurrence. To identify the specific effect of postoperative BUN, it was further divided into quartiles to explore the different influences on the $\mathrm{CSDH}$ recurrence in each category. The local ethics committee ruled that no formal ethics approval was required in this particular study.

\section{Statistical analysis}

Data for continuous variables were shown as mean \pm standard deviation or medians and interquartile range. To verify whether the data follows a normal distribution or not, Kolmogorov-Smirnov test was performed. Categorical variables were shown as relative frequencies and percentages. Normally distributed variables were compared by Student's t-test, whereas the Mann-Whitney U test was used for the asymmetrically distributed
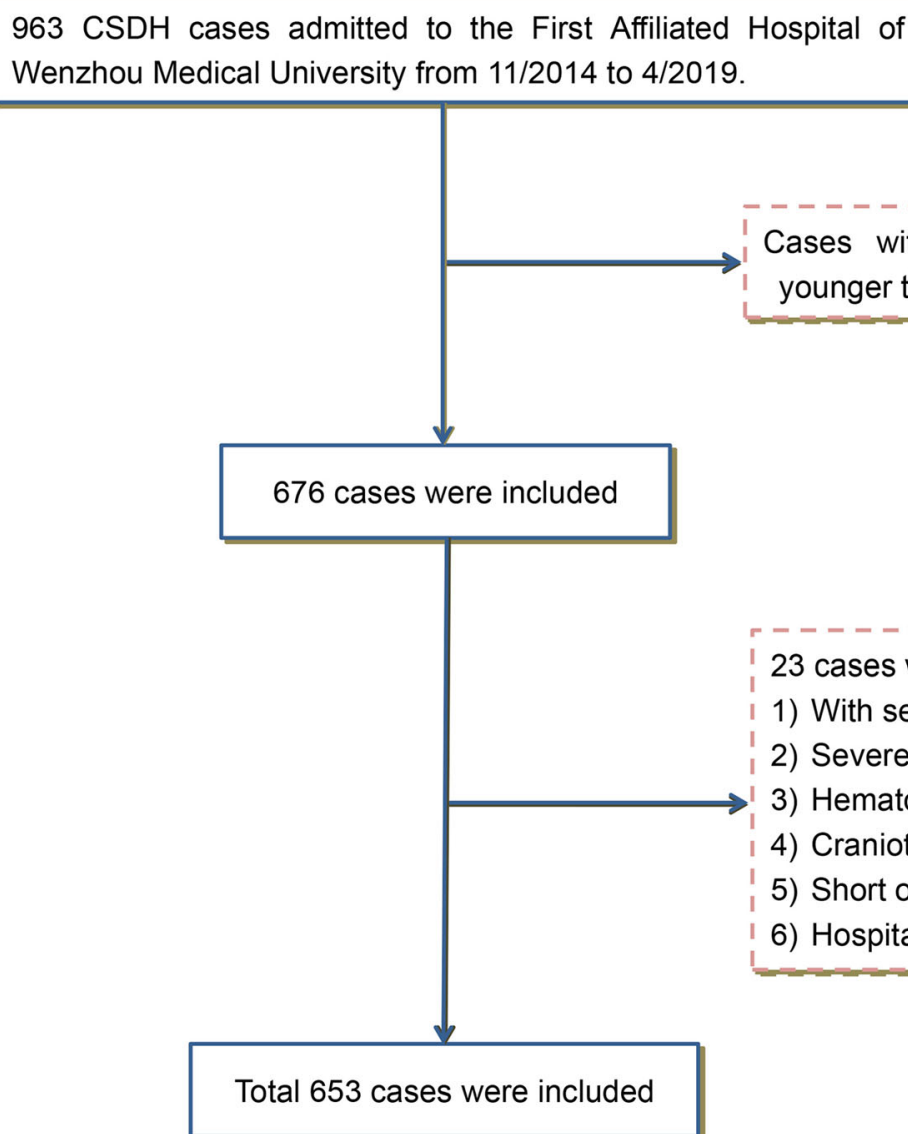

Cases without surgical treatment and patients younger than 18 were excluded $(n=287)$

23 cases were excluded:

1) With severe epilepsy $(n=1)$

2) Severe renal or blood diseases $(n=5)$

3) Hematoma organized or bad operation result $(n=2)$

4) Craniotomy or evacuated by other departments $(n=6)$

5) Short of perioperative laboratory investigation $(n=1)$

6) Hospital mortality $(n=8)$

Fig. 2 Study flow diagram. CSDH, chronic subdural hematoma 
Table 1 Clinical and Demographic Characteristics of Patients with CSDH

\begin{tabular}{|c|c|c|c|c|}
\hline Variables & $\begin{array}{l}\text { All patients } \\
(N=653)\end{array}$ & Recurrence $(n=96)$ & Non-Recurrence $(n=557)$ & $P$-value \\
\hline Postoperative BUN (mmol/L) & $4.9(4,6.4)$ & $5.9(4.4,6.9)$ & $4.9(3.9,6.3)$ & $<0.001$ \\
\hline \multicolumn{5}{|l|}{ Demographic parameters } \\
\hline Age (years) & $72(64,80)$ & $75(69,82)$ & $71(63,80)$ & 0.012 \\
\hline Gender & & & & 0.263 \\
\hline Male, n (\%) & $561(85.9 \%)$ & $86(89.6 \%)$ & $475(85.3 \%)$ & \\
\hline Female, n (\%) & $92(14.1 \%)$ & $10(10.4 \%)$ & $82(14.7 \%)$ & \\
\hline Current drinking, n (\%) & $234(35.8 \%)$ & $34(35.4 \%)$ & $200(35.9 \%)$ & 0.926 \\
\hline Current smoking, n (\%) & $237(36.3 \%)$ & $33(34.4 \%)$ & $204(36.6 \%)$ & 0.672 \\
\hline Baseline SBP (mmHg) & $138(126,153)$ & $135(124,151)$ & $140(127,153)$ & 0.122 \\
\hline Baseline DBP (mmHg) & $79(71,87)$ & $77(71,84)$ & $79(71,87)$ & 0.091 \\
\hline \multicolumn{5}{|l|}{ Laboratory investigation } \\
\hline Blood glucose (mmol/L) & $5.5(4.7,6.6)$ & $5.7(5,6.7)$ & $5.4(4.7,6.6)$ & 0.265 \\
\hline $\mathrm{Cr}(\mu \mathrm{mol} / \mathrm{L})$ & $67(58,77)$ & $68(60,80)$ & $66(57,77)$ & 0.097 \\
\hline Leukocyte $(X 10 \wedge 9 / L)$ & $6.94(5.81,8.43)$ & $6.51(5.52,7.55)$ & $7.01(5.85,8.62)$ & 0.010 \\
\hline Neutrophil $(X 10 \wedge 9 / L)$ & $4.62(3.68,6.15)$ & $4.30(3.51,5.31)$ & $4.70(3.71,6.26)$ & 0.012 \\
\hline Lymphocyte (X10^9/L) & $1.46(1.10,1.81)$ & $1.46(1.17,1.83)$ & $1.47(1.1,1.81)$ & 0.650 \\
\hline Erythrocyte $(X 10 \wedge 12 / L)$ & $4.23 \pm 0.51$ & $4.19 \pm 0.52$ & $4.24 \pm 0.51$ & 0.379 \\
\hline Hemoglobin (g/L) & $132(120,142)$ & $132(119,142)$ & $132(119,140)$ & 0.442 \\
\hline Platelet (X10^9/L) & $211(172,249)$ & $194(164,239)$ & $213(175,251)$ & 0.010 \\
\hline Prothrombin Time(s) & $13.3(12.8,13.9)$ & $13.4(12.8,14.0)$ & $13.3(12.8,13.9)$ & 0.642 \\
\hline INR & $1.02(0.97,1.08)$ & $1.02(0.98,1.10)$ & $1.02(0.97,1.07)$ & 0.719 \\
\hline Fibrinogen (g/L) & $3.61(3.09,4.28)$ & $3.50(2.89,4.15)$ & $3.64(3.15,4.30)$ & 0.046 \\
\hline \multicolumn{5}{|l|}{ Comorbidities } \\
\hline Hypertension, n (\%) & $252(38.6 \%)$ & $40(41.7 \%)$ & $212(38.1 \%)$ & 0.503 \\
\hline Diabetes mellitus, n (\%) & $77(11.8 \%)$ & $11(11.5 \%)$ & $66(11.8 \%)$ & 0.913 \\
\hline Cardiovascular disease, n (\%) & $42(6.4 \%)$ & $6(6.3 \%)$ & $36(6.5 \%)$ & 0.937 \\
\hline \multicolumn{5}{|l|}{ Medication use } \\
\hline Atorvastatin therapy, n (\%) & $478(73.2 \%)$ & $74(77.1 \%)$ & $404(72.5 \%)$ & 0.352 \\
\hline PAMBA therapy, n (\%) & $189(28.9 \%)$ & $26(27.1 \%)$ & $163(29.3 \%)$ & 0.663 \\
\hline Hematoma location & & & & 0.957 \\
\hline Unilateral left, n (\%) & $288(44.1 \%)$ & $42(43.8 \%)$ & $246(44.2 \%)$ & \\
\hline Unilateral right, n (\%) & $216(33.1 \%)$ & $31(32.3 \%)$ & $185(33.2 \%)$ & \\
\hline Bilateral, n (\%) & $149(22.8 \%)$ & $23(24.0 \%)$ & $126(22.6 \%)$ & \\
\hline Postoperative bleeding & $136(20.8 \%)$ & 22 (22.9\%) & $114(20.5 \%)$ & 0.585 \\
\hline GOS at discharge & & & & 0.549 \\
\hline $5, \mathrm{n}(\%)$ & $593(90.8 \%)$ & $90(93.8 \%)$ & $503(90.3 \%)$ & \\
\hline $4, \mathrm{n}(\%)$ & $48(7.4 \%)$ & $5(5.2 \%)$ & $43(7.7 \%)$ & \\
\hline $3, \mathrm{n}(\%)$ & $12(1.8 \%)$ & $1(1.0 \%)$ & $11(2.0 \%)$ & \\
\hline Preoperative investigation & $N=632$ & $n=95$ & $n=537$ & \\
\hline BUN (mmol/L) & $5.3(4.4,6.5)$ & $5.9(4.8,6.9)$ & $5.2(4.3,6.4)$ & 0.001 \\
\hline
\end{tabular}

NOTE. SBP, systolic blood pressure; DBP, diastolic blood pressure; $\mathrm{Cr}$, creatinine; INR, international normalized ratio; PAMBA, para-aminomethylbenzoic acid; BUN, blood urea nitrogen; GOS, Glasgow Outcome Scale 
continuous variables. Chi-squared $\left(x^{2}\right)$ test was used to compare categorical variables. Statistical comparisons among BUN concentrations stratification were estimated by one-way analysis of variance (ANOVA) or KruskalWallis test for continuous variables, and Pearson's chisquare test for categorical variables where appropriate. Wilcoxon signed-rank test was performed to compare the difference between pre and post-operative BUN levels. Odds ratio (OR) and 95\% confidence interval (CI) for recurrence risk were calculated by performing multivariate-adjusted binary logistic regression. Restricted cubic spline regressions model was built to examine the linear relation between serum BUN concentration and the risk of recurrence. In this study, a twotailed $p$-value less than $0.05(P<0.05)$ was considered as statistical significance. All statistical analyses were done using SPSS (version 23.0, IBM Corp.) and STATA software (version 12, StataCorp LP) was employed to analyze the restricted cubic spline regressions.

\section{Results}

Baseline characteristics of all cases in the recurrence group and non-recurrence group

A total of $653 \mathrm{CSDH}$ cases were enrolled in this study (Fig. 2). This study group included 561 male cases $(85.9 \%)$ and 92 female cases (14.1\%). Patient's age ranged from 21 to 100 years with a median of 72 years (interquartile range 64 to 80 years). (Table 1 ). 8 patients with hospitalized mortality were excluded and there was no mortality upon follow-up in this study.

The descriptive characteristics between groups with and without recurrence are shown in Table 1, including the demographics, laboratory, imaging, medication and comorbidity characteristics. In this study, 96 (14.7\%) cases were diagnosed as CSDH recurrence, including 16 patients who needed a second operation. Compared with non-recurrence, the cases in the group of recurrence were older and have lower levels of serum leukocyte, neutrophil and platelet count. However, lower serum fibrinogen concentration was examined in recurrence cases $(P<0.05)$. Moreover, there was a statistical difference between pre and post-operative groups on serum BUN concentration $(P=0.001$ and $P<0.001$, respectively). Table 2 revealed that the BUN level of the pre-operative group was significantly higher than the post-operative BUN level in the non-recurrence group $(P<0.001)$ while it showed no obvious difference in the recurrence group.

\section{Baseline characteristics of all cases in BUN quartiles}

For further exploration, the cases were divided into 4 groups based on quartiles of the postoperative BUN concentration. The cut-off points for this stratification of the BUN concentration into quartiles were: $\mathrm{Q} 1 \leq 4.0$ $\mathrm{mmol} / \mathrm{L}, \quad 4.0<\mathrm{Q} 2 \leq 4.9 \mathrm{mmol} / \mathrm{L}, \quad 4.9<\mathrm{Q} 3 \leq 6.4 \mathrm{mmol} / \mathrm{L}$ and $\mathrm{Q} 4>6.4 \mathrm{mmol} / \mathrm{L}$. Table 3 summarizes the characteristics of the CSDH cases by the quartiles of BUN. Cases with different postoperative BUN concentration appeared to be similar in most features except for age, $\mathrm{Cr}$, erythrocyte and hemoglobin. These factors would be adjusted for multivariate-adjusted binary logistic regression for good measure. 22 (14\%) of 157 patients in the highest quartile of BUN suffered moderate disability at discharge which was statistically higher than in other quartiles.

\section{Association between the BUN concentrations and recurrence}

Significant differences were observed between the recurrence and non-recurrence groups in BUN concentration quartiles of cases $(P=0.003)$. The proportion of cases in the lowest quartile $(\leq 4.0 \mathrm{mmol} / \mathrm{L})$ was dramatically low in the recurrence group $(P=0.027)$, whilst the proportion of cases in the highest quartile $(>6.4 \mathrm{mmol} / \mathrm{L})$ was significantly high in the recurrence group $(P=0.012)$ (Table 4).

In Table 5, with all cases taken as a whole, the condition that $\mathrm{CSDH}$ recurrence was interpreted as a dependent variable and the lowest quartile was interpreted as the reference was used for postoperative BUN level in the binary logistic regression models. The highest quartile of BUN concentration $(>6.4 \mathrm{mmol} / \mathrm{L})$ was independently estimated as a risk factor of $\mathrm{CSDH}$ recurrence with an unadjusted OR of 3.315 (95\%CI: 1.711-6.423, $P<0.001)$. After adjusting for the confounders including sex, age, current alcohol drinking, current smoking, comorbidities (hypertension, diabetes mellitus, coronary heart disease), medicine (Atorvastatin and PAMBA), and laboratory investigation (platelet, fibrinogen, leukocyte, erythrocyte, hemoglobin, $\mathrm{Cr}$ ), the

Table 2 The comparison between pre- and post-operative BUN levels

\begin{tabular}{llll}
\hline Variable & Preoperative BUN $(\mathbf{m m o l} / \mathbf{L})$ & Postoperative BUN $(\mathbf{m m o l} / \mathbf{L})$ & $P$-value \\
\hline Total $(n=632)$ & $5.3(4.4,6.5)$ & $4.9(4.0,6.4)$ & $<0.001$ \\
Recurrence $(n=95)$ & $5.9(4.8,6.9)$ & $5.85(4.4,6.9)$ & 0.177 \\
Non-Recurrence $(n=537)$ & $5.2(44.3,6.4)$ & $4.9(3.9,6.25)$ & $<0.001$ \\
\hline
\end{tabular}

BUN, blood urea nitrogen; 
Table 3 Baseline Characteristics of Patients with Chronic Subdural Hematoma according to postoperative BUN quartile

\begin{tabular}{|c|c|c|c|c|c|}
\hline \multirow[t]{2}{*}{ Variables } & \multicolumn{5}{|l|}{ BUN quartiles } \\
\hline & $\begin{array}{l}\text { quartile } 1 \\
n=170(\leq 4.0)\end{array}$ & $\begin{array}{l}\text { quartile } 2 \\
n=162(>4.0, \leq 4.9)\end{array}$ & $\begin{array}{l}\text { quartile } 3 \\
n=164(>4.9, \leq 6.4)\end{array}$ & $\begin{array}{l}\text { quartile } 4 \\
n=157(>6.4)\end{array}$ & $P$-value \\
\hline $\mathrm{BUN}(\mathrm{mmol} / \mathrm{L})$ & $3.4(3.0,3.7)$ & $4.5(4.3,4.8)$ & $5.7(5.3,6.0)$ & $7.4(6.9,8.3)$ & $<0.001$ \\
\hline \multicolumn{6}{|l|}{ Demographic parameters } \\
\hline Age (years) & $68(61,76)$ & $72(63,79)$ & $73(66,82)$ & $76(69,83)$ & $<0.001$ \\
\hline Gender, male, n (\%) & $140(82.4 \%)$ & $148(91.4 \%)$ & 141 (86.0\%) & 132 (84.1\%) & 0.103 \\
\hline Current drinking, n (\%) & $61(35.9 \%)$ & $62(38.3 \%)$ & $58(35.4 \%)$ & $53(33.8 \%)$ & 0.866 \\
\hline Current smoking, n (\%) & $68(39.4 \%)$ & $56(34.6 \%)$ & $63(38.4 \%)$ & $51(32.5 \%)$ & 0.526 \\
\hline Baseline SBP $(\mathrm{mmHg})$ & $138.4 \pm 19.4$ & $139.3 \pm 19.7$ & $141.0 \pm 20.6$ & $142.5 \pm 21.0$ & 0.274 \\
\hline Baseline DBP (mmHg) & $79(71,87)$ & $79(73,86)$ & $77(72,88)$ & $78(71,87)$ & 0.984 \\
\hline \multicolumn{6}{|l|}{ Laboratory investigation } \\
\hline Blood glucose (mmol/L) & $5.5(4.8,6.5)$ & $5.6(4.7,6.6)$ & $5.6(4.7,6.8)$ & $5.4(4.5,6.7)$ & 0.818 \\
\hline $\mathrm{Cr}(\mu \mathrm{mol} / \mathrm{L})$ & $60(54,68)$ & $66(57,75)$ & $69(60,80)$ & $74(63,87)$ & $<0.001$ \\
\hline Leukocyte $(X 10 \wedge 9 / L)$ & $7.00(6.14,8.45)$ & $6.97(5.81,8.62)$ & $6.98(5.73,8.33)$ & $6.77(5.55,8.39)$ & 0.677 \\
\hline Neutrophil (X10^9/L) & $4.78(3.84,6.31)$ & $4.68(3.76,6.30)$ & $4.52(3.59,5.92)$ & $4.52(3.60,5.95)$ & 0.369 \\
\hline Lymphocyte (X10^9/L) & $1.50(1.10,1.80)$ & $1.40(1.10,1.71)$ & $1.50(1.11,1.87)$ & $1.45(1.10,1.81)$ & 0.518 \\
\hline Erythrocyte $(X 10 \wedge 12 / L)$ & $4.30 \pm 0.51$ & $4.27 \pm 0.50$ & $4.24 \pm 0.52$ & $4.12 \pm 0.52$ & 0.008 \\
\hline Hemoglobin $(g / L)$ & $133(120,144)$ & $133(123,142)$ & $132(120,144)$ & $130(116,139)$ & 0.047 \\
\hline Platelet $(X 10 \wedge 9 / L)$ & $219(174,259)$ & $206(175,250)$ & $203(175,243)$ & $201(162,249)$ & 0.183 \\
\hline Prothrombin Time (s) & $13.3(12.7,13.8)$ & $13.2(12.9,13.9)$ & $13.4(12.9,13.9)$ & $13.4(12.9,14.1)$ & 0.523 \\
\hline INR & $1.02(0.97,1.07)$ & $1.02(0.97,1.08)$ & $1.03(0.97,1.08)$ & $1.03(0.97,1.10)$ & 0.484 \\
\hline Fibrinogen $(\mathrm{g} / \mathrm{L})$ & $3.55(3.11,4.38)$ & $3.71(3.10,4.35)$ & $3.61(2.97,4.18)$ & $3.67(3.12,4.26)$ & 0.740 \\
\hline \multicolumn{6}{|l|}{ Comorbidities } \\
\hline Hypertension, n (\%) & $61(35.9 \%)$ & $61(37.7 \%)$ & $60(36.6 \%)$ & $70(44.6 \%)$ & 0.355 \\
\hline Diabetes mellitus, n (\%) & $18(10.6 \%)$ & $18(11.1 \%)$ & $17(10.4 \%)$ & $24(15.3 \%)$ & 0.480 \\
\hline Cardiovascular disease, n (\%) & $9(5.3 \%)$ & $10(6.2 \%)$ & $11(6.7 \%)$ & $12(7.6 \%)$ & 0.853 \\
\hline \multicolumn{6}{|l|}{ Medication use } \\
\hline Atorvastatin therapy, n (\%) & $124(72.9 \%)$ & $118(72.8 \%)$ & $114(69.5 \%)$ & $122(77.7 \%)$ & 0.427 \\
\hline PAMBA therapy, n (\%) & $40(23.5 \%)$ & $45(27.8 \%)$ & $53(32.3 \%)$ & $51(32.5 \%)$ & 0.222 \\
\hline Hematoma location & & & & & 0.367 \\
\hline Unilateral left, n (\%) & $68(40.0 \%)$ & $82(50.6 \%)$ & $75(45.7 \%)$ & $63(40.1 \%)$ & \\
\hline Unilateral right, n (\%) & $62(36.5 \%)$ & $48(29.6 \%)$ & $55(33.5 \%)$ & $51(32.5 \%)$ & \\
\hline Bilateral, n (\%) & $40(23.5 \%)$ & $32(19.8 \%)$ & 34 (20.7\%) & $43(27.4 \%)$ & \\
\hline GOS at discharge & & & & & 0.042 \\
\hline $5, \mathrm{n}(\%)$ & $160(94.1 \%)$ & 149 (92.0\%) & 152 (92.7\%) & 132 (84.1\%) & \\
\hline 4, n (\%) & $8(4.7 \%)$ & $10(6.2 \%)$ & $8(4.9 \%)$ & $22(14 \%)$ & \\
\hline $3, \mathrm{n}(\%)$ & $2(1.2 \%)$ & $3(1.9 \%)$ & $4(2.4 \%)$ & $3(1.9 \%)$ & \\
\hline
\end{tabular}

NOTE. SBP, systolic blood pressure; DBP, diastolic blood pressure; Cr, creatinine; INR, international normalized ratio; PAMBA, para-aminomethylbenzoic acid; BUN, blood urea nitrogen; GOS, Glasgow Outcome Scale

highest quartile of BUN remained significantly and independently associated with $\mathrm{CSDH}$ recurrence (model 1 : OR $=2.892,95 \%$ CI:1.463-5.717, $P=0.002$; model 2 : OR $=2.939,95 \%$ CI:1.480-5.836, $P=0.002$; model 3 : $\mathrm{OR}=3.069,95 \% \mathrm{CI}: 1.488-6.330, P=0.002)$. There was no multicollinearity between the independent variables in model 3. Furthermore, restricted cubic spline regressions were used to explore the linear relationship between BUN concentration and the risk of CSDH recurrence (Fig. 3). Most importantly, it could be observed visually that the highest quartile had a significantly high OR value. 
Table 4 BUN quartiles of patients

\begin{tabular}{lllll}
\hline Variable & Recurrence $(\mathbf{n}=\mathbf{9 6})$ & Non-Recurrence $(\mathbf{n}=\mathbf{5 5 7})$ & $\mathbf{X}^{\mathbf{2}}$ & 14.308 \\
\hline BUN (mmol/L) & & & 4.870 & 0.003 \\
Quartile 1 $(\leq 4.0)$ & $14(14.6 \%)$ & $156(28.0 \%)$ & 0.132 \\
Quartile 2(>4.0, $\leq 4.9)$ & $22(22.9 \%)$ & $140(25.1 \%)$ & 0.027 \\
Quartile 3(>4.9, $\leq 6.4)$ & $24(25.0 \%)$ & $140(25.1 \%)$ & 0.000 & 0.717 \\
Quartile 4(>6.4) & $36(37.5 \%)$ & $121(21.7 \%)$ & 6.283 \\
\hline
\end{tabular}

\section{Discussion}

To the best of our knowledge, this is the first study to investigate the association between BUN concentration and the recurrence of $\mathrm{CSDH}$ after evacuation. Our results indicated that high postoperative BUN concentration was related to the prevalence of CSDH recurrence within 3 months after the operation. Our findings hence suggest that the postoperative BUN concentration could be an available risk factor for CSDH recurrence.

BUN is a waste product of protein catabolism which is linked with poor prognosis and mortality in acute or chronic heart failure [12]. In addition, a study of 3355 AIS patients by You et al. observed that higher BUN had a 3.75-fold higher risk of in-hospital mortality [11]. In the present study, we found that patients with a relatively higher level of BUN were more likely to be moderately disabled at discharge. This was consistent with the previous studies that elevated BUN levels during hospitalization was related to a poor outcome. However,

Table 5 Multivariate adjusted odds ratios for the association between BUN levels and Recurrence

\begin{tabular}{lllll}
\hline & Quartile & OR $^{\mathbf{a}}$ & $\mathbf{9 5 \% C l}$ & $\boldsymbol{P}_{\text {-value }}$ \\
\hline Unadjusted & Middle & 1.751 & $0.863-3.554$ & 0.121 \\
& Higher & 1.910 & $0.951-3.837$ & 0.069 \\
& Highest & 3.315 & $1.711-6.423$ & $<0.001$ \\
Model 1 $^{\mathrm{b}}$ & Middle & 1.590 & $0.778-3.252$ & 0.204 \\
& Higher & 1.713 & $0.842-3.483$ & 0.137 \\
& Highest & 2.892 & $1.463-5.717$ & 0.002 \\
Model 2 $^{\mathrm{c}}$ & Middle & 1.612 & $0.788-3.299$ & 0.191 \\
& Higher & 1.768 & $0.866-3.611$ & 0.118 \\
& Highest & 2.939 & $1.480-5.836$ & 0.002 \\
Model 3 & Middle & 1.612 & $0.780-3.333$ & 0.197 \\
& Higher & 1.733 & $0.837-3.590$ & 0.139 \\
& Highest & 3.069 & $1.488-6.330$ & 0.002 \\
\hline
\end{tabular}

$\mathrm{OR}$, odds radio; $\mathrm{Cl}$ confidence level; $\mathrm{Cr}$, creatinine; Recurrence of postoperative $\mathrm{CSDH}$

${ }^{\text {a }}$ Reference OR (1.000) is the lowest quartile of BUN for Recurrence of CSDH

${ }^{b}$ Model 1: adjusted for age, sex, current smoking, current alcohol drinking

c Modal 2: adjusted for covariates from Model 1 and further adjusted for medical history (coronary heart disease, diabetes mellitus, hypertension) and medicine (Atorvastatin and PAMBA)

${ }^{d}$ Modal 3: adjusted for covariates from Model 2 and further adjusted for Platelet, Fibrinogen, Leukocyte, Erythrocyte, Hemoglobin, $\mathrm{Cr}$ little data was found on the relationship between BUN and recurrence of CSDH. In this study, we observed that cases with a higher BUN level presented a trend toward a higher recurrence rate of CSDH. Furthermore, elevated BUN was associated with an enhanced risk of CSDH recurrence and cases with the highest postoperative BUN ( $>6.4 \mathrm{mmol} / \mathrm{L}$ ) seemed to have a 3.069-fold increase in danger of CSDH recurrence after adjusting for the potential confounders. The normal range of BUN level in the research hospital is $2.8-7.2 \mathrm{mmol} / \mathrm{L}$ which means the majority of patients presented with BUN level in the normal range. The BUN levels reflected not only the renal function but also other reactions that were mentioned below. In this study, the $\mathrm{Cr}$ level did not have an effect on the recurrence of $\mathrm{CSDH}$ which means there was no direct association between renal function and CSDH recurrence. The cutoff value of the postoperative BUN level in this study is $6.4 \mathrm{mmol} / \mathrm{L}$ and it indicated that the normal range of BUN level for intracranial lesion might be different from the systematic level. Also, elevated preoperative BUN levels showed an association with the recurrence of $\mathrm{CSDH}$ after logistic regression (See Supplemental Table, Additional file 1). Comparison between pre and post-operative BUN levels revealed that the BUN in the non-recurrence group significantly decreased after evacuation while it did not occur in the recurrence group, further confirming the relationship between BUN and CSDH recurrence.

The precise mechanisms underlying the association between elevated BUN and CSDH recurrence remained unclear. A potential explanation for this might be that a systemic increase in serum BUN induces intracranial multiple responses, which in turn can produce hematoma expansion and bring out CSDH recurrence. Some studies have revealed that the predictive value of BUN may be induced by its connection with other variables, such as protein intake, protein catabolism, nitrogen production and neurohormonal activation [12, 13]. On the other hand, CSDH was recently suggested to be formed through complex processes including angiogenesis, fibrinolysis and inflammation [14], and the recurrence of CSDH follows the same process as formation. There is strong evidence to show that vascular endothelial growth factor (VEGF) was related to the generation 


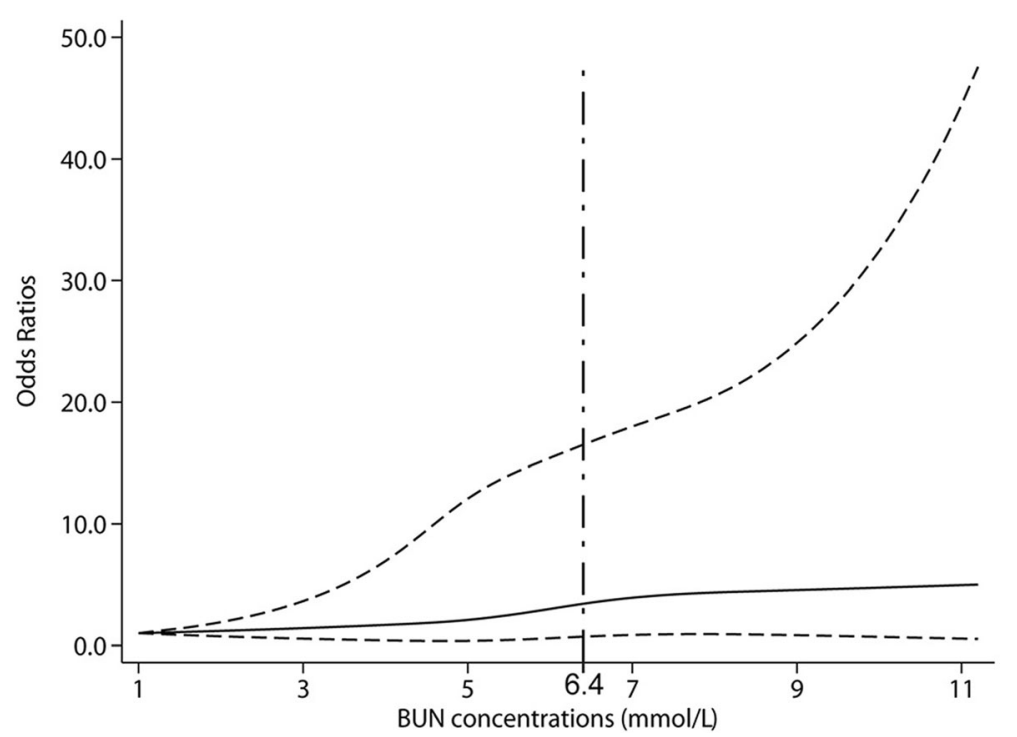

Fig. 3 Association of BUN levels with risk of Recurrence. Dashed lines are $95 \%$ confidence intervals. Dotted line is where BUN concentration is 6.4 $\mathrm{mmol} / \mathrm{L}$. Odds ratios and $95 \%$ confidence intervals derived from restricted cubic spline regression. Odds ratios were estimated using logistic regression modeling, adjusting for the same variables as model 3 in Table 5

and steady increase of CSDH fluid volume [15-17] as well as the risk of CSDH recurrence [18]. Interestingly, Lin et al. observed that VEGF expression was positively correlated with BUN [19]. Hence, these discoveries might explain the relatively good correlation between elevated BUN and CSDH recurrence.

Compared with CSDH cases without recurrence, our result also showed that CSDH cases with recurrence had significantly higher age, which is consistent with the reports of previous studies $[7,20]$. However, we found that the older cases were associated with higher BUN and the difference of patient age was not statistically significant after multivariate logistic regression analysis though age affects the recurrence of CSDH through the change of BUN.

Additionally, decreased fibrinogen level was found to be associated with the CSDH recurrence. In fact, fibrinogen has been proven to be a potentially available risk factor for postoperative intracranial bleeding [21, 22] considering that elevating serum fibrinogen was targeted as a valid therapy for intracranial hemorrhage [23]. Moreover, high levels of fibrinogen degradation products (FDPs) have been examined in CSDH fluid $[24,25]$ and fresh red cells were identified within CSDH fluid [24], suggesting that bleeding is an essential part of CSDH formation. The current study did not reveal a significant difference between postoperative atorvastatin use and CSDH recurrence. This finding runs contrary to existing studies [26, 27], hence, making the relationship between atorvastatin administration and CSDH recurrence puzzling.

There were a few limitations recognized in the present study. First, this study is a retrospective study and the selection bias is inevitable. Secondly, this is only a single-center clinical finding, which may impact the generalization of the results, thus further prospective research with plenty of patients might be required. Finally, considering that the role BUN plays in the CSDH recurrence is still confusing, more studies need to be pursued to further and better delineate CSDH formation in the future.

\section{Conclusion}

The most obvious finding from this study was that elevated BUN at post-operation was independently associated with the recurrence of CSDH. The result suggested that a high level of postoperative BUN might serve as a risk factor of $\mathrm{CSDH}$ recurrence, so the determination of serum BUN after evacuation is important for patients with CSDH. Further prospective studies need to be undertaken to validate the causal relationship between BUN and CSDH recurrence.

\section{Supplementary Information}

The online version contains supplementary material available at https://doi. org/10.1186/s12883-020-01985-w.

Additional file 1. Supplemental table of multivariate analyzed association between preoperative BUN and Recurrence.

Additional file 2. The complete data used and analysed during the current study.

\section{Abbreviations}

CSDH: Chronic subdural hematoma; BUN: Blood Urea Nitrogen; BHI: Burr-hole irrigation; GCS: Glasgow coma score; CT: Computed tomography;

MRI: Magnetic resonance imaging; AIS: Acute ischemic stroke; GOS: Glasgow Outcome Scale; ANOVA: Analysis of variance; OR: Odds ratio; Cl: Confidence interval; Cr: Creatinine; PAMBA: Para-aminomethylbenzoic acid; SBP: Systolic 
blood pressure; DBP: Diastolic blood pressure; INR: International normalized ratio; VEGF: Vascular endothelial growth factor; FDPs: Fibrinogen degradation products

\section{Acknowledgments}

Not applicable.

\section{Authors' contributions}

NW, JH and AO wrote the manuscript. NW performed the statistical analyses. $N W, X Z$ and $Y L$ gathered the data and are responsible for the integrity of registered data. LR, JY and QZ designed and coordinated the study. SY contributed to the analysis and interpretation of data. The authors read and approved the submitted version.

\section{Funding}

This work was supported by grants from the National Natural Science Foundation of China (No. 81771262), Zhejiang Health Science and Technology Project (2016RCA022), Zhejiang Provincial Natural Science Foundation of China (LQ20H090005) and Wenzhou Municipal Science and Technology Bureau Project of China (Y20190568)

\section{Availability of data and materials}

The datasets used and analyzed during the current study are available in supported Additional file 2 and the confidential patient data was erased.

\section{Ethics approval and consent to participate}

The ethics committee of Wenzhou Medical University First Affiliated Hospital ruled that no formal ethics approval was required in this retrospective study and determined that informed consent was not required.

\section{Consent for publication}

Not applicable.

\section{Competing interests}

All authors certify that they have no affiliations with or involvement in any organization or entity with any financial interest (such as honoraria; educational grants; participation in speakers' bureaus; membership, employment, consultancies, stock ownership, or other equity interest; and expert testimony or patent-licensing arrangements), or non-financial interest (such as personal or professional relationships, affiliations, knowledge or beliefs) in the subject matter or materials discussed in this manuscript.

\section{Author details}

'Zhejiang Provincial Key Laboratory of Aging and Neurological Disorder Research, The First Affiliated Hospital of Wenzhou Medical University, Wenzhou 325000, China. ${ }^{2}$ Department of Neurosurgery, The First Affiliated Hospital of Wenzhou Medical University, Wenzhou 325000, Zhejiang, China. ${ }^{3}$ Department of Pharmacology and Neuroscience, University of North Texas Health Science Center, Fort Worth, TX 76107, USA.

Received: 10 March 2020 Accepted: 29 October 2020 Published online: 10 November 2020

\section{References}

1. Ducruet AF, Grobelny BT, Zacharia BE, Hickman ZL, DeRosa PL, Andersen $\mathrm{KN}$, et al. The surgical management of chronic subdural hematoma. Neurosurg Rev. 2012;35(2):155-69discussion 69. https://doi.org/10.1007/ s10143-011-0349-y.

2. Rauhala M, Luoto TM, Huhtala H, Iverson GL, Niskakangas T, Ohman J, et al. The incidence of chronic subdural hematomas from 1990 to 2015 in a defined Finnish population. J Neurosurg. 2019:1-11. https://doi.org/10.3171/ 2018.12.JNS183035.

3. Kolias AG, Chari A, Santarius T, Hutchinson PJ. Chronic subdural haematoma: modern management and emerging therapies. Nat Rev Neurol. 2014;10(10): 570-8. https://doi.org/10.1038/nrneurol.2014.163.

4. You CG, Zheng XS. Postoperative pneumocephalus increases the recurrence rate of chronic subdural hematoma. Clin Neurol Neurosurg. 2018;166:56-60. https://doi.org/10.1016/j.clineuro.2018.01.029

5. Wang Y, Zhou J, Fan C, Wang D, Jiao F, Liu B, et al. Influence of antithrombotic agents on the recurrence of chronic subdural hematomas and the quest about the recommencement of antithrombotic agents: a meta-analysis. J Clin Neurosci. 2017;38:79-83. https://doi.org/10.1016/j.jocn. 2016.12.001.

6. Rust T, Kiemer N, Erasmus A. Chronic subdural haematomas and anticoagulation or anti-thrombotic therapy. J Clin Neurosci. 2006;13(8):8237. https://doi.org/10.1016/j.jocn.2004.12.013.

7. Leroy HA, Aboukais R, Reyns N, Bourgeois P, Labreuche J, Duhamel A, et al. Predictors of functional outcomes and recurrence of chronic subdural hematomas. J Clin Neurosci. 2015;22(12):1895-900. https://doi.org/10.1016/j. jocn.2015.03.064.

8. Schrock JW, Glasenapp M, Drogell K. Elevated blood urea nitrogen/ creatinine ratio is associated with poor outcome in patients with ischemic stroke. Clin Neurol Neurosurg. 2012;114(7):881-4. https://doi.org/10.1016/j. clineuro.2012.01.031.

9. Lin CJ, Yang JT, Huang YC, Tsai YH, Lee MH, Lee M, et al. Favorable outcome of blood urea nitrogen/creatinine-based hydration therapy 3 months after acute ischemic stroke. Am J Emerg Med. 2016;34(12):2414-8. https://doi.org/10.1016/j.ajem.2016.09.033.

10. Deng L, Wang C, Qiu S, Bian H, Wang L, Li Y, et al. Association between blood urea nitrogen-to-creatinine ratio and three-month outcome in patients with acute ischemic stroke. Curr Neurovasc Res. 2019;16(2):166-72. https://doi.org/10.2174/1567202616666190412123705.

11. You S, Zheng D, Zhong C, Wang X, Tang W, Sheng L, et al. Prognostic significance of blood urea nitrogen in acute ischemic stroke. Circ J. 2018; 82(2):572-8. https://doi.org/10.1253/circj.CJ-17-0485.

12. Damman K, Voors AA, Navis G, van Veldhuisen DJ, Hillege HL. Current and novel renal biomarkers in heart failure. Heart Fail Rev. 2012;17(2):241-50. https://doi.org/10.1007/s10741-011-9254-2.

13. Schrier RW. Blood urea nitrogen and serum creatinine: not married in heart failure. Circ Heart Fail. 2008;1(1):2-5. https://doi.org/10.1161/ CIRCHEARTFAILURE.108.770834

14. Edlmann E, Giorgi-Coll S, Whitfield PC, Carpenter KLH, Hutchinson PJ. Pathophysiology of chronic subdural haematoma: inflammation, angiogenesis and implications for pharmacotherapy. J Neuroinflammation. 2017;14(1):108. https://doi.org/10.1186/s12974-017-0881-y.

15. Weigel R, Hohenstein A, Schilling L. Vascular endothelial growth factor concentration in chronic subdural hematoma fluid is related to computed tomography appearance and exudation rate. J Neurotrauma. 2014;31(7): 670-3. https://doi.org/10.1089/neu.2013.2884.

16. Shono T, Inamura T, Morioka T, Matsumoto K, Suzuki SO, Ikezaki K, et al. Vascular endothelial growth factor in chronic subdural haematomas. J Clin Neurosci. 2001;8(5):411-5. https://doi.org/10.1054/jocn.2000.0951.

17. Hua $C$, Zhao G, Feng $Y$, Yuan $H$, Song $H$, Bie L. Role of matrix Metalloproteinase-2, matrix Metalloproteinase-9, and vascular endothelial growth factor in the development of chronic subdural hematoma. J Neurotrauma. 2016;33(1):65-70. https://doi.org/10.1089/neu.2014.3724.

18. Hong HJ, Kim YJ, Yi HJ, Ko Y, Oh SJ, Kim JM. Role of angiogenic growth factors and inflammatory cytokine on recurrence of chronic subdural hematoma. Surg Neurol. 2009;71(2):161-5discussion 5-6. https://doi.org/10. 1016/j.surneu.2008.01.023.

19. Lin S, Teng J, Li J, Sun F, Yuan D, Chang J. Association of Chemerin and Vascular Endothelial Growth Factor (VEGF) with diabetic nephropathy. Med Sci Monit. 2016;22:3209-14. https://doi.org/10.12659/msm.896781.

20. Motoie R, Karashima S, Otsuji R, Ren N, Nagaoka S, Maeda K, et al. Recurrence in 787 patients with chronic subdural hematoma: retrospective cohort investigation of associated factors including direct Oral anticoagulant use. World Neurosurg. 2018;118:e87-91. https://doi.org/10. 1016/j.wneu.2018.06.124

21. Zhang XH, Wang QM, Chen $\mathrm{H}$, Chen $\mathrm{YH}$, Han W, Wang FR, et al. Clinical characteristics and risk factors of intracranial hemorrhage in patients following allogeneic hematopoietic stem cell transplantation. Ann Hematol. 2016;95(10):1637-43. https://doi.org/10.1007/s00277-016-2767-y.

22. Adelmann D, Klaus DA, Illievich UM, Krenn CG, Krall C, Kozek-Langenecker S, et al. Fibrinogen but not factor XIII deficiency is associated with bleeding after craniotomy. Br J Anaesth. 2014;113(4):628-33. https:/doi.org/10.1093/bja/aeu133.

23. McBride D, Tang J, Zhang JH. Maintaining plasma fibrinogen levels and fibrinogen replacement therapies for treatment of intracranial hemorrhage. Curr Drug Targets. 2017;18(12):1349-57. https://doi.org/10.2174/ 1389450117666151209123857.

24. Ito H, Yamamoto S, Komai T, Mizukoshi H. Role of local hyperfibrinolysis in the etiology of chronic subdural hematoma. J Neurosurg. 1976;45(1):26-31. https://doi.org/10.3171/jns.1976.45.1.0026. 
25. Heula AL, Ohlmeier S, Sajanti J, Majamaa K. Characterization of chronic subdural hematoma fluid proteome. Neurosurgery. 2013;73(2):317-31. https://doi.org/10.1227/01.neu.0000430323.24623.de.

26. Tang R, Shi J, Li X, Zou Y, Wang L, Chen Y, et al. Effects of atorvastatin on surgical treatments of chronic subdural hematoma. World Neurosurg. 2018; 117:e425-e9. https://doi.org/10.1016/j.wneu.2018.06.047.

27. Jiang R, Zhao S, Wang R, Feng H, Zhang J, Li X, et al. Safety and efficacy of atorvastatin for chronic subdural hematoma in Chinese patients: a randomized ClinicalTrial. JAMA Neurol. 2018;75(11):1338-46. https://doi.org/ 10.1001/jamaneurol.2018.2030.

\section{Publisher's Note}

Springer Nature remains neutral with regard to jurisdictional claims in published maps and institutional affiliations.

Ready to submit your research? Choose BMC and benefit from:

- fast, convenient online submission

- thorough peer review by experienced researchers in your field

- rapid publication on acceptance

- support for research data, including large and complex data types

- gold Open Access which fosters wider collaboration and increased citations

- maximum visibility for your research: over $100 \mathrm{M}$ website views per year

At BMC, research is always in progress.

Learn more biomedcentral.com/submissions 